\title{
A Comparative Study to Evaluate the Effectiveness of 3D Digital Models and Study Cast to Measure Anteroposterior Anchorage Loss in Patients Treated with Preadjusted Edgewise Appliance
}

\author{
Kavitha Oadthurai Marusamy*, Raghad Khalid Abuarab, Meelad Mahmood Bin Jahlan, Lina \\ Waseem Qureshi and Rahaf Hamed Alahmadi
}

Dental College, Ibn Sina National College of Medical Sciences, Jeddah, Kingdom of Saudi Arabia; dr.omkavitha@gmail.com

\begin{abstract}
Anchorage loss is an important parameter in controlling the outcome of orthodontic treatment. Lateral cephalogram and study model analysis are routinely used to monitor anchorage loss. Study is to evaluate the effectiveness of 3D digital model and study cast to measure maxillary molar anchorage loss in patients treated with fixed orthodontic appliance. A total of 31 high anchorage patients who were treated with pre adjusted edgewise appliance for their malocclusions were included in the study. Amount of horizontal anchorage loss was measured by two methods: Study cast and 3D digital model super imposition. The anterior palatal rugae area was taken as a reference point for comparative measurements. Paired t-test was performed to compare the mean values of anchorage loss measured on both methods. When we compared the mean anchorage loss of two methods, it was found that there were no statistically significant differences observed for both the right side $(t=0.513, p>0.05)$ and left side $(t=-0.081, p>0.05)$. The spearman correlation between two methods showed a very strong correlation in both right $(\mathrm{r}=0.919)$ and left side $(\mathrm{r}=0.906)$ which was statistically significant $(\mathrm{p}<0.001)$. The present study shows that the measurement of anchorage loss using 3D digital superimpositions is equally reliable as that of study models. Thus, 3D digital models present as an alternative method to the measurement of anteroposterior anchorage loss.
\end{abstract}

Keywords: Anchorage Loss, Fixed Orthodontics, 3D Digital Models, Study Cast

\section{Introduction}

Orthodontic treatment involves substantial forces for retraction and aligning teeth. These forces generate opposite reciprocal forces of the same magnitude resulting in anchorage loss. Anchorage loss is a potential cause for failure of orthodontic mechanotherapy ${ }^{1}$. The extracted tooth position, additional appliance, age of the patient, degree of crowding and over jet determines the anchorage loss. Planning anchorage control with adequate intra or extra oral anchorage devices such as Trans-Palatal Arch
(TPA), Nance appliance, involvement of multiple teeth as anchorage segment, extra oral and skeletal anchorage system will resist or stabilize the molar position ${ }^{2}$.

Measurement of anchorage loss at every stage of treatment can help the orthodontist to achieve the planned treatment objectives. Measurement of anchorage loss is commonly done on cephalometric superimposition and study cast measurement, has been considered the reliable methods to determine the movement of teeth with respect to stable reference points ${ }^{3}$. Superimposition of cephalometric radiographs requires multiple radiation

*Author for correspondence 
exposures, distortion due to different magnification and many clinicians desist from routinely using this method ${ }^{4}$.

Study models have been used as a most accepted method of anchorage loss. But they have many disadvantages such as likelihood of infection, can wear away plaster which leads to losing of anatomical details of the cast thus decreasing accuracy, study models can break, storage needs space $^{5}$. During stage record, making impression for study cast is difficult as the impression material can tear and also dislodge the orthodontic brackets. An alternative method using an intraoral scanner and producing ThreeDimensional (3D) digital models is gaining popularity.

3D digital models' usage is increasing because of its convenience. Continuous development of 3D digital laser scanner and software technology leads to very accurate transformation of scanned data into images. Superimposition of $3 \mathrm{D}$ virtual models can offer more detailed information on orthodontic tooth movement in comparison with traditional two-dimensional cephalometric analysis ${ }^{6,7}$.

Digital orthodontic record systems with integrated digital photos and radiographic records are replacing stone study casts with $3 \mathrm{D}$ digital models ${ }^{8-10}$. So, the present study was formulated to evaluate the effectiveness of 3D scanning and study cast to measure anteroposterior anchorage loss in patients treated with pre adjusted edgewise appliance.

\section{Materials and Methods}

The current research compared the effectiveness of two different methods in measuring anteroposterior anchorage loss in patients treated with pre-adjusted edgewise appliance. Records of 31 maximum anchorage patients (16 males, 15 females; mean $18.54 \pm 7.8$ years) with Class II division 1 malocclusion treated in the Department of preventive dentistry, Ibn Sina National College Dental Hospital were included in the study. The study was approved by the institutional review board (Ethical committee approval no H-16-11072019). Consent of the patients were obtained after being informed that their records might be anonymously used for research purpose at later stage.

Depending upon the degree of the malocclusion, patterns of orthodontic tooth movement can vary. A minimum age of treatment as 18 years for male patients and 14 years for female patients was fixed to minimize the post treatment growth effect.
The fixed orthodontic treatment started with 0.022 " $\times 0.028$ " bracket slot dimension of MBT prescription. Maxillary second molars were banded and included to increase the posterior anchorage. Consequently, the arches were aligned and leveled with 0.019 " x 0.025 " Stainless Steel wire. Alignment was considered to be complete and recorded after 6 weeks without any active force. Post-alignment records (3D digital model and Study cast) were taken at this stage. Pretreatment and post alignment records were analyzed and amount of Anteroposterior anchorage loss measured in millimeters.

To calculate the amount of horizontal anchorage loss an acrylic palatal jig was fabricated on the pretreatment study model. The anterior palatal vault (rugae area) was used as a reference point for the placement for the palatal jig. The acrylic jig was fabricated with reference wires (0.045 stainless steel) embedded that extended to the mesial fossa of first molars ${ }^{4,11}$. The acrylic jig was constructed for every patient using the pre-treatment model (Figure 1).

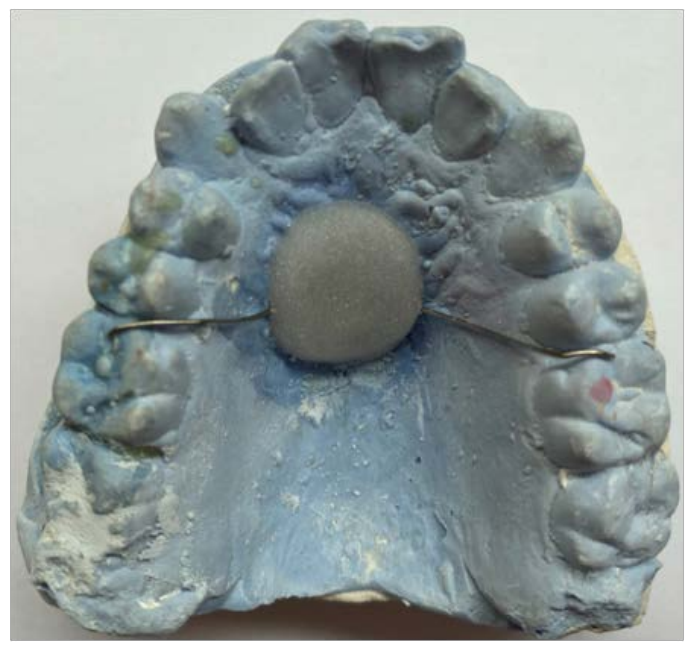

Figure 1. Fabrication of palatal acrylic jig for measurement of horizontal molar movement on cast.

The pretreatment model was used to fabricate the jig which was then fitted on the stable reference point i.e., palatal rugae on the final model after completion of alignment. The distance between the initial positions of the wire to the final position was measured at the molar region with the help of Vernier calipers to calculate the molar anchorage loss in each subject.

$3 \mathrm{D}$ digital models were acquired at pre- and posttreatment using a 3D laser scanning system (Stratasys D900L 3D scanner). The accuracy of the models were \pm $0.02 \mathrm{~mm}$ for $10 \mathrm{~mm}$ and a resolution of $1,024 \times 768$ pixels. 
Using Rapid form 2006 software (INUS Technology, Seoul, Korea) 3D surface-to-surface matching with medial end of $3 \mathrm{rd}$ rugae as a reference point was performed (Figure 2).

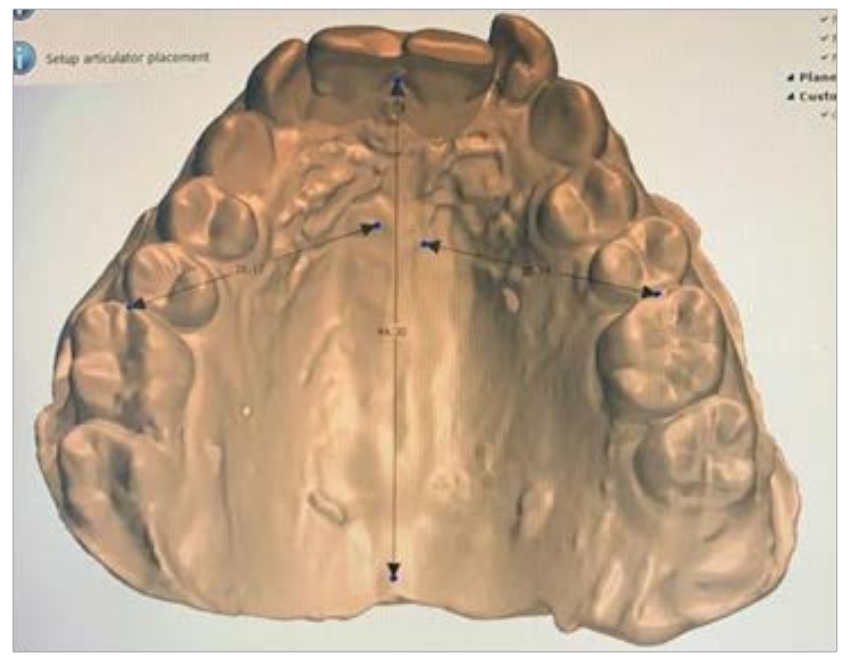

Figure 2. Pretreatment digitalized cast with reference points \& measurement of linear variable.

\section{Statistics}

Statistical differences between two groups were analyzed with Independent student's ' $t$ ' test. Spearman's correlation test was used to analyze degree of correlation between study cast and 3D digital casts measuring anchorage loss.

\section{Results}

A total of 31 samples were analyzed for two methods of measurement a) study cast and b) 3D superimposition. The mean anchorage loss in the study cast was found to be $3.56 \pm 1.22$ for the right side and $3.47 \pm 1.19$ for the left side. When the right-side 3D Superimposition showed a mean anchorage loss of $3.52 \pm 1.13$, the left side had a mean value of $3.48 \pm 1.14$ (Table 1 ).
When we compared the mean anchorage loss of two methods, there were no statistically significant differences observed for both groups, right side $(\mathrm{t}=0.513, \mathrm{p}>0.05)$ and left side $(t=-0.081, p>0.05)$ (Table 2). The spearman correlation between two methods showed a very strong correlation in both right $(\mathrm{r}=0.919)$ (Figure 3$)$ and left side $(\mathrm{r}=0.906)$ (Figure 4$)$ which was statistically significant, $\mathrm{p}$ $<0.001$ (Table 3).

\section{Discussion}

Study models provide a permanent record of a patient's malocclusion, useful to discuss proposed treatment plan with patients and to visualize the treatment process. Study models can also be useful for helping to monitor the results of patient's treatment during follow-up visits. In Clinical orthodontic practice, diagnostic measurements have been traditionally made on plaster dental casts. Storage of study models is problematic in terms of space constraints and cost. The application of three-dimensional imaging is becoming more accessible and practical. The various applications of 3D technology in the field of orthodontics have allowed for advances in diagnosis, treatment planning, and orthodontic techniques. Superimpositions of these images provide a comparison to established norms and templates, the determination of changes resulting from treatment or growth, as well as a prediction of potential treatment outcomes ${ }^{12}$.

Many software programs are available to perform 3D superimpositions. Each of these different methods, techniques, and software differ in their ease of use, efficiency, accuracy, time required, and cost. With the use of $3 \mathrm{D}$ superimpositions being relatively new to the field of orthodontics, its potential for use in the research and clinical settings is still in its early stages. As technology and techniques improve, registration of 3D images will become faster, easier, and more efficient to help transform

Table 1. Mean of two methods

\begin{tabular}{|c|c|c|c|c|c|c|}
\hline & & $\mathrm{N}$ & Mean & Std. Deviation & Minimum & Maximum \\
\hline \multirow{2}{*}{ STUDY CAST WITH ACRYLIC JIG } & RIGHT & 31 & 3.565 & 1.222 & 1.470 & 5.980 \\
\cline { 2 - 7 } & LEFT & 31 & 3.475 & 1.197 & 1.520 & 6.430 \\
\hline \multirow{2}{*}{ STUDYCAST 3D SUPERIMPOSITION } & RIGHT & 31 & 3.521 & 1.128 & 1.370 & 5.650 \\
\cline { 2 - 7 } & LEFT & 31 & 3.483 & 1.141 & 1.260 & 5.440 \\
\hline
\end{tabular}


Table 2. Comparison of two methods

\begin{tabular}{|c|c|c|c|c|c|c|c|}
\hline & \multirow{2}{*}{$\begin{array}{c}\text { Mean } \\
\text { difference }\end{array}$} & \multirow[t]{2}{*}{ SD } & \multirow{2}{*}{$\begin{array}{l}\text { Std. Error } \\
\text { Mean }\end{array}$} & \multicolumn{2}{|c|}{$\begin{array}{l}\text { 95\% Confidence Interval of } \\
\text { the Difference }\end{array}$} & \multirow[t]{2}{*}{ 't' value } & \multirow[t]{2}{*}{ P value } \\
\hline & & & & Lower & Upper & & \\
\hline $\begin{array}{c}\text { STUDY CAST WITH } \\
\text { ACRYLIC JIG RIGHT } \\
\text { VS STUDYCAST 3D } \\
\text { SUPERIMPOSITION } \\
\text { RIGHT }\end{array}$ & .04419 & .48032 & .08627 & -.13199 & .22038 & .512 & 0.612 (NS) \\
\hline $\begin{array}{c}\text { STUDY CAST WITH } \\
\text { ACRYLIC JIG LEFT } \\
\text { VS STUDYCAST 3D } \\
\text { SUPERIMPOSITION } \\
\text { LEFT }\end{array}$ & -.00742 & .50891 & .09140 & -.19409 & .17925 & -.081 & 0.936 (NS) \\
\hline
\end{tabular}

${ }^{*} \mathrm{P}$ value $\leq 0.05$ is considered statistically significant

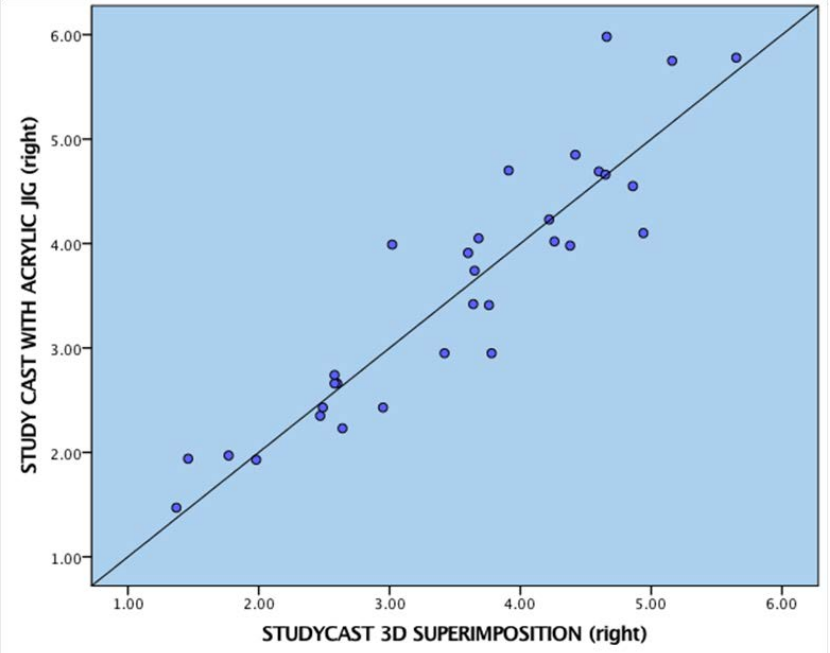

Figure 3. Correlation between study cast acrylic jig and study cast 3D superimposition (Right).

Table 3. Correlations

\begin{tabular}{|c|c|c|c|}
\hline & $\mathrm{N}$ & $\begin{array}{c}\text { Spearman } \\
\text { Correlation }\end{array}$ & $P$ value \\
\hline $\begin{array}{c}\text { STUDY CAST WITH } \\
\text { ACRYLIC JIG RIGHT } \\
\text { VS STUDYCAST 3D } \\
\text { SUPERIMPOSITION } \\
\text { RIGHT }\end{array}$ & 31 & 919 & $<0.001$ \\
\hline $\begin{array}{c}\text { STUDY CAST WITH } \\
\text { ACRYLIC JIG LEFT } \\
\text { VS STUDYCAST 3D } \\
\text { SUPERIMPOSITION } \\
\text { LEFT }\end{array}$ & 31 & .906 & $<0.001$ \\
\hline
\end{tabular}

${ }^{\star} \mathrm{P}$ value $\leq 0.05$ is considered statistically significant

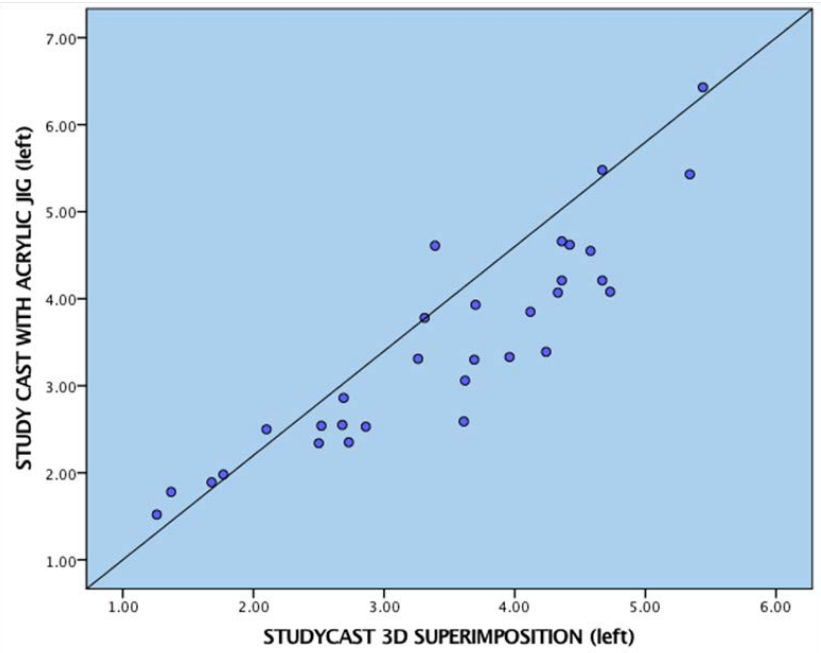

Figure 4. Correlation between study cast acrylic jig and study cast 3D superimposition (Left).

and advance the way orthodontists diagnose and treat patients $^{13}$.

Intraoral scanning is faster, reduces patient discomfort, and simplifies the impression procedures for the dentist, eliminating plaster models and cross contamination. Digital models allow better communication with the dental technician and also explaining the treatment with the patients. Intra oral scanners are not very accurate in crowded teeth, there is a steep learning curve with high initial costs of setup ${ }^{14}$. In comparative studies, intra oral optical scanner was less accurate than model scanning which implies that the intraoral conditions (saliva, limited spacing) may contribute to the inaccuracy of a $\operatorname{scan}^{15,16}$. 
Digital models can be easily stored, can be transferred electronically to colleagues, specialists, and insurance companies. They are also an excellent tool for patient education ${ }^{17}$. The present digital generation can be more comfortable with computer-generated images. Digital models can be manipulated to show the possible future treatment outcomes in malocclusion to the patient and their parents during pre-treatmentdiscussion ${ }^{18}$.

For fabrication of crowns and short fixed partial dentures, digital impression techniques are becoming more acceptable ${ }^{19}$. Currently, intraoral scans are time consuming. In a clinical study of comparing chair side impressions and digital scanning, $73.3 \%$ of patients preferred impressions because that was faster. $26.7 \%$ preferred the scan because it was "more comfortable. With digital technology continuous to progress, intraoral scanning is gaining more acceptance among orthodontic clinicians ${ }^{20,21}$.

\section{Conclusion}

There was no statistically significant difference in the quantum of anchor loss between 3D virtual models' system and Conventional study casts. Considering that $3 \mathrm{D}$ digital models are efficient in planning, reducing discomfort and increased treatment efficacy, they are effective tools to measure anchorage loss in fixed orthodontic patients.

\section{References}

1. Venkatesh S, Rozario J, Ganeshkar SV, Ajmera S. Comparative evaluation of sagittal anchorage loss in lingual and labial appliances during space closure: A pilot study. APOS Trends in Orthodontics. 2014 Dec 29; 5(1):33-7. https://doi.org/10.4103/2321-1407.148027

2. Siva Krishna P, Prasad M, Gowri Sankar S, Reddy GV. Anchorage In Orthodontics: A Literature Review. Annals and Essences of Dentistry. 2016; 8(2):7-19

3. Doppel. An investigation of maxillary superimposition techniques using metallic implants. Am J Orthod Dentofacial Orthop. 1994; 105:161-8. https://doi. org/10.1016/S0889-5406(94)70112-1

4. Hoggan BR, Sadowsky C. The use of palatal rugae for the assessment of anteroposterior tooth movements. Am J Orthod Dentofacial Orthop. 2001; 119:482-8. https://doi. org/10.1067/mod.2001.113001 PMid:11343019

5. Abizadeh N, Moles DR, O’Neill J, Noar JH. Digital versus plaster study models: How accurate and reproducible are they? J Orthod. 2012 Sep 1; 39(3):151-9. https://doi.org/10. 1179/1465312512Z.00000000023PMid:22984099

6. Thiruvenkatachari B, Al-Abdallah M, Akram NC, Sandler J, O’Brien K. Measuring 3-imensionaltooth movement with a 3-dimensional surface laser scanner. Am J Orthod Dentofacial Orthop. 2009; 135:480-5. https://doi. org/10.1016/j.ajodo.2007.03.040 PMid:19361734

7. Cho MY, Choi JH, Lee SP, Baek SH. Three-dimensional analysis of the tooth movement and arch dimension changes in Class I malocclusions treated with first premolar extractions: a guideline for virtual treatment planning. Am J Orthod Dentofacial Orthop. 2010; 138:747-57. https:// doi.org/10.1016/j.ajodo.2008.11.033 PMid:21130334

8. Sjögren AP1, Lindgren JE, Huggare JA. Orthodontic study cast analysis--reproducibility of recordings and agreement between conventional and 3D virtual measurements. J Digit Imaging. 2010 Aug; 23(4):482-92. https://doi.org/10.1007/ s10278-009-9211-y PMid:19526268 PMCid:PMC3046658

9. Aragón ML, Pontes LF, Bichara LM. Flores-Mir Validity and reliability of intraoral scanners compared to conventional gypsum models measurements: A systematic review. C2, Normando Eur J Orthod. 2016 Aug; 38(4):429-34. https:// doi.org/10.1093/ejo/cjw033 PMid:27266879

10. Keul C, Güth JF. Accuracy of full-arch digital impressions: an in vitro and in vivo comparison. Clin Oral Investig. 2020 Feb; 24(2):735-45. https://doi.org/10.1007/s00784-01902965-2 PMid:31134345

11. Nambiar S, Mogra S, Shetty S, Shetty S. Assessment of anteroposterior and transverse first premolar extraction changes using palatal rugae and comparative analysis with lateral cephalogram in Angle's Class I and II patients: An institutional retrospective study. J Orthod Res. 2013; 1:45-51. https://doi.org/10.4103/2321-3825.116284

12. Bell A, Ayoub AF, Siebert P. Assessment of the accuracy of a three-dimensional imaging system for archiving dental study models. J Orthod. 2003 Sep; 30(3):219-23. https:// doi.org/10.1093/ortho/30.3.219 PMid:14530419

13. Saleh WK, Ariffin E, Sherriff M, Bister D. Accuracy and reproducibility of linear measurements of resin, plaster, digital and printed study-models. J Orthod. 2015 Oct 2; 42(4):301-6. https://doi.org/10.1179/14653133 15Y.0000000016 PMid:26216658

14. Mangano F, Gandolfi A, Luongo G, Logozzo S. Intraoral scanners in dentistry: a review of the current literature. BMC oral health. 2017 Dec 1; 17(1):149. https://doi.org/10.1186/ s12903-017-0442-x PMid:29233132 PMCid:PMC5727697

15. Flügge TV, Schlager S, Nelson K, Nahles S, Metzger MC. Precision of intraoral digital dental impressions with iTero and extraoral digitization with the iTero and a model scanner. Am J Orthod Dentofacial Orthop. 2013; 
144:471-8. https://doi.org/10.1016/j.ajodo.2013.04.017 PMid:23992820

16. Vogel AB, Kilic F, Schmidt F, Rübel S, Lapatki BG. Optical 3D scans for orthodontic diagnostics performed on fullarch impressions. Completeness of surface structure representation. J Orofac Orthop. 2015; 76:493-507. https:// doi.org/10.1007/s00056-015-0309-1 PMid:26250455

17. Sanches JO, Santos-Pinto LA, Santos-Pinto AD, Grehs B, Jeremias F. Comparison of space analysis performed on plaster vs. digital dental casts applying Tanaka and Johnston's equation. Dental Press J Orthod. 2013 Feb; 18(1):12833. https://doi.org/10.1590/S2176-94512013000100024 PMid:23876960

18. Rheude B, Sadowsky PL, Ferriera A, Jacobson A. An evaluation of the use of digital study models in orthodontic diagnosis and treatment planning. Angle Orthod. 2005; 75:300-4.
19. Ahlholm P, Sipilä K Vallittu P, Jakonen M, Kotiranta U. Digital versus conventional impressions in fixed prosthodontics: A review. Prosthodont. 2018 Jan; 27(1):3541. doi: 10.1111/jopr.12527. https://doi.org/10.1111/ jopr.12527 PMid:27483210

20. Grünheid T, McCarthy SD, Larson BE. Clinical use of a direct chairside oral scanner: An assessment of accuracy, time, and patient acceptance. Am J Orthod Dentofacial Orthop. 2014; 146:673-862. https://doi.org/10.1016/j. ajodo.2014.07.023 PMid:25439218

21. Naidu D, Freer TJ. Validity, reliability, and reproducibility of the IOC intraoral scanner: A comparison of tooth widths and Bolton ratios. Am J Orthod Dentofacial Orthop. 2013; 144:304-310. https://doi.org/10.1016/j.ajodo.2013.04.011 PMid:23910212 